\title{
Complex Role of Hypnotizability in the Cognitive Control of Pain
}

\author{
Enrica L. Santarcangelo* and Sybille Consoli \\ Department of Translational Research and New Technologies in Medicine and Surgery University of Pisa, Pisa, Italy
}

Keywords: hypnotizability, analgesia, BISBAS, cerebellum, expectation, insula, suggestions, pain

This opinion article deals with the role of hypnotizability in the efficacy of the suggestions of analgesia for the cognitive control of pain and of its physiological correlates.

Hypnotizability is a multimensional trait including suggestibility (Raz, 2007) and other characteristics such as fantasy proneness, attitude to be deeply absorped in specific tasks/mental images (Green and Lynn, 2011; Dasse et al., 2015), strong functional equivalence between imagery and perception (Papalia et al., 2014; Santarcangelo, 2014; Ibanez-Marcelo et al., 2018). It predicts the proneness to accept suggestions (Green et al., 2005; Elkins et al., 2015) and is measured by scales so that the general population is classified as high (highs, about 15\%), medium (mediums, about 70\%) and low (lows, about 15\%) susceptible to hypnosis (De Pascalis et al., 2000). In the ordinary state of consciousness and in the absence of specific suggestions, different levels of hypnotizability are associated with different cerebral (Landry et al., 2017), cerebellar (Bocci et al., 2017; Picerni et al., 2018), sensorimotor and cardiovascular characteristics (Santarcangelo and Scattina, 2016).

The paper describes the interaction between explicit suggestions of analgesia and the expectation of pain relief (Huber et al., 2013; De Pascalis and Scacchia, 2016) on the basis of new findings regarding the hypnotisability-related polymorphism of opioid receptors $\mu 1$ (Presciuttini et al., 2018). In addition, the paper reports the observed joined influence of hypnotisability and cognitive-emotional traits (Madeo et al., 2015; Jensen et al., 2016) conceptualized as Behavioral Inhibition/Activation System (BIS/BAS) (Gray, 1990) and as Interoception/Interoceptive Awareness (Sebastiani et al., 2018; Varanini et al., 2018) on pain. Finally, the paper proposes that the observed morpho-functional peculiarities of the highs' salience network-insula, cingulate and prefrontal cortex (Landry et al., 2017) - and cerebellum (Bocci et al., 2017; Picerni et al., 2018) may play a role in the complex role of hypnotizability in pain modulation. In this respect, it should be noted that, although hypnotisability is an approximately stable individual trait, socio-cognitive factors such as relational disposition and the manipulation of expectation can modulate the efficacy of suggestions (Kirsch, 2018). The possible biological substrates for some of these factors, for instance the oxytocn release during hypnotic interventions, are now emerging (Kasos et al., 2018).

\section{HYPNOTIZABILITY AND SUGGESTIONS FOR ANALGESIA}

Suggestions are explicit instructions aimed at modifying perception, memory and behavior (Braffman and Kirsch, 1999). The suggestions for analgesia are widely employed owing to their efficacy in the cognitive control of pain, which can be predicted by the subjects' hypnotizability scores (Dillworth et al., 2012; Enea et al., 2014; Koban et al., 2017).

Hypnotisability scores predict the efficacy of the suggestions for analgesia in both the ordinary state of consciousness-that is in the absence of any procedure of hypnotic inductionand under hypnosis (Milling et al., 2005; Derbyshire et al., 2009; Meyer and Lynn, 2011). Explicit suggestions for analgesia can be associated or not with instructions for relaxation and pleasant imagery (Zachariae and Bjerring, 1994; Carlson et al., 2017; Hamlin and Robertson, 2017). Personalized suggestions (Berna et al., 2012; Koban et al., 2017) can be prepared for each patient according to her/his preference and directed to the sensory (Hofbauer et al., 2001) or cognitive-affective dimension of pain (Rainville et al., 1997) or both (Feldman, 2009). 
Neuroimaging studies (Del Casale et al., 2015) have shown that in highs the suggestions for analgesia modulate the functional connectivity among the regions of the pain matrix being able to modify pain perception, attention to pain, defensive responses and any other component of pain experience and behavior (Faymonville et al., 2003; Zeev-Wolf et al., 2016). EEG and EMG studies have also shown that in highs the suggestions for analgesia decrease pain and both cortical activity (De Pascalis et al., 1999, 2015; Valentini et al., 2013) and nociceptive reflexes (Kiernan et al., 1995; Danziger et al., 1998). Also mediums may respond to suggestions for analgesia, although to a lower extent (Fidanza et al., 2017). This enhances the number of subjects who may benefit from suggestion-induced analgesia from 15 to $85 \%$ of the general population (Montgomery et al., 2002a,b; Milling et al., 2006, 2007).

\section{HYPNOTIZABILITY AND EXPECTATION OF PAIN RELIEF}

Highs are more responsive than lows and mediums not only to the explicit suggestions of analgesia, but also to the conditioned analgesia, or Diffuse Noxious Inhibitory Control (Sandrini et al., 2000; Fidanza et al., 2017) which is mediated by endogenous opioids (Granot et al., 2008). This suggests that expectationinduced mechanisms, which are more effective in highs than in lows, are associated with those sustaining the conditioned analgesia. However, in highs the expectation of pain relief does not totally account for the suggestion induced analgesia (Gearan and Kirsch, 1993) and it is unlikely that the expectation of analgesia could be sustained by opioid mechanisms, in contrast to the general population (Amanzio and Benedetti, 1999; Benedetti et al., 1999; Petrovic et al., 2002; Zubieta et al., 2005; Scott et al., 2008; Babel et al., 2017). In fact, not only the effects of

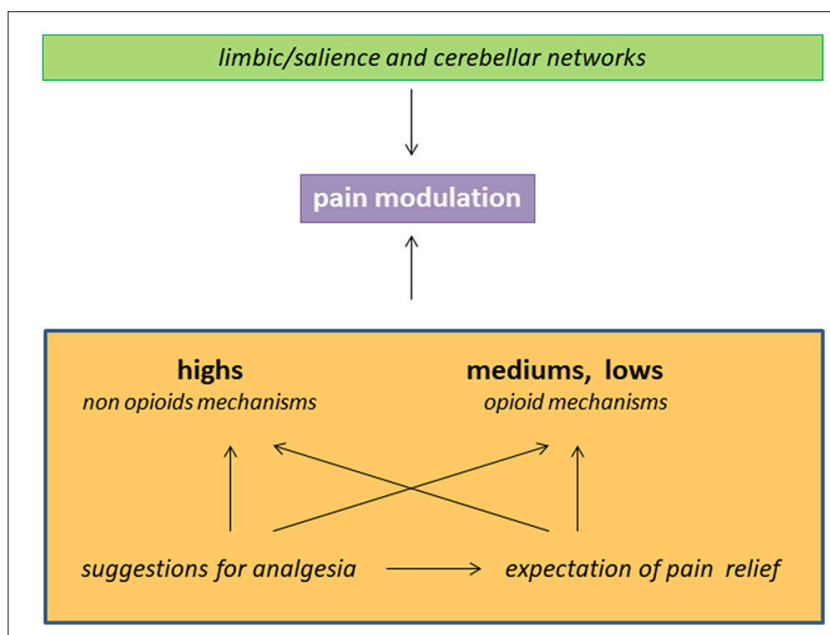

FIGURE 1 | Schematic representation of factors and mechanisms involved in pain reduction in the subjects with different hypnotizability. The interaction between limbic/salience networks and the cerebellum may sustain hypnotisability-related BIS/BAS traits and interoception and influence the response to the suggestions of analgesia. The latter can be associated with expectation of pain relief and act through hypnotisability-related mechanisms. suggestions is not abolished by naloxone (Moret et al., 1991) but, in addition, highs display the $\mu 1$ polymorphism (Presciuttini et al., 2018) which has been found associated with low sensitivity to opiates, low placebo response (Trescot and Faynboym, 2014; Bartošová et al., 2015; Peciña and Zubieta, 2015) and larger opiates consumption for post-surgery (Zhang et al., 2005; Boswell et al., 2013; Sia et al., 2013; Ren et al., 2015) and cancer pain (Gong et al., 2013; Wan et al., 2015; Yao et al., 2015).

In the general population, pain is associated with modulation of the activation and fuctional connectivity of the "pain matrix" that is the brain region sustaining the varions dimensions of pain (Legrain et al., 2011). It includes the primary and secondary somatosensory areas, the insula and the anterior cingulate cortex. The emergence of pain depends on the flow and integration of information among these areas and is a function of indidual characteristics and of the context (Iannetti and Mouraux, 2010).

Both explicit suggestions and placebo responses are due to top-down mechanisms (Zunhammer et al., 2018), but it has been shown that, in correspondence of similar subjective response to expectation-induced placebo, highs and lows exhibit opposite patterns of activity and functional connectivity (Huber et al., 2013). In fact, the former exhibit reduced functional connectivity between the right dorsolateral prefrontal cortex (rDLPC) and the anterior midcingulate/medial prefrontal cortex, the left inferior frontal gyrus and the right cerebellum. In addition, placebo analgesia is associated with deactivation in the thalamus, basal ganglia, left precuneus and bilateral temporal gyrus only in highs. The observed differences are in line with earlier findings indicating that in the general population placebo analgesia is sustained by circuits involved in the regulation of emotional processes (Amanzio et al., 2011).

An observation relevant to clinical interventions, however, is that an experimental session including relaxation or distraction and suggestions for analgesia modulates pain experience also in chronic pain patients with low hypnotizability scores (Carli et al., 2008). This does not challenge the predictive role of hypnotizability as in lows analgesia is not time-locked with suggestions. This finding can be accounted for by a possible strong motivation to analgesia due to the presence of chronic pain, inducing expectation-induced placebo responses following suggestions (Hyland, 2011; Benedetti, 2013; Benedetti and Amanzio, 2013; Carlino et al., 2014) and making them indirectly effective also in lows. Thus, the suggestions for analgesia represent an easy and cheap tool for the cognitive control of pain in the large majority of acute (also procedure-related) and chronic pain patients (Elkins et al., 2007; Jensen et al., 2009; Stoelb et al., 2009; Didier et al., 2011; Jensen and Patterson, 2014; Mendoza et al., 2017a,b; Waisblat et al., 2017).

\section{INTERACTION OF HYPNOTISABILITY WITH THE BEHAVIORAL INHIBITION/ACTIVATION SYSTEM AND INTEROCEPTION ABILITIES}

Recent findings have challenged the established relation between the analgesic effects of suggestions and hypnotizability. In 
fact, the interaction between hypnotizability and cognitive emotional traits such as those sustained by the Behavioral Inhibition/Activation System (BIS/BAS) (Gray, 1990) in pain imagery (Santarcangelo et al., 2013) and control (Jensen et al., 2016) and in its cortical correlates (Madeo et al., 2015) suggests hypnotizability may be just one of the factors involved in pain control by suggestions of analgesia.

BIS/BAS is based in limbic circuits (Gray, 1990; Angelides et al., 2017), concerns the proneness to approach or withdraw from possibly pleasant and unpleasant conditions, respectively, and is measured by scales (Carver, 2004). BIS is considered an attentional system sensitive to possible punishment, non-reward and novelty, while BAS reflects the motivation to follow one's goals and to approach fun and reward. High BIS is associated with enhanced attention, arousal and vigilance, high BAS with impulsivity, bipolar and attention deficit/ hyperactivity (De Pascalis et al., 2010). In particular, BIS/BAS modulates pain in patients with headache (Jensen et al., 2015) and muskuloskeletal pain (Serrano-Ibáñez et al., 2018).

It has been shown that, even in the absence of significant differences between highs' and lows' scores, the BISBAS activity masks the hypnotizability-related differences in the vividness of pain imagery (Santarcangelo et al., 2013) and that the activity of BIS/BAS rather than hypnotizability itself is responsible for the hypnotizability-related EEG differences observed during tonic nociceptive stimulation associated and not associated with suggestions for analgesia in highs. On the other hand, in chronic pain patients the relation between BIS/BAS and hypnotizability is not linear (Jensen et al., 2016), which indicates a complex interaction.

Another trait potentially influencing the relation between hypnotisability and the effect of the suggestions for analgesia is the ability of interoception that is to detect and interpret bodily states and their changes pre-eminently related to the activity of the autonomic system. Interoceptive signals are monitored and processed at several levels of the central nervous system such as the insula, the orbitofrontal cortex and the cingulate cortex (Critchley and Harrison, 2013) and interoception has been found altered in mental disorders (Murphy et al., 2017; Khalsa et al., 2018) and chronic pain patients (Di Lernia et al., 2016). The role of interoception in pain has been found different in healthy highs and lows. In fact, a correlation between resting heart rate and pain threshold after suggestions of analgesia has been found in highs undergoing cold pressor test, but not in lows

\section{REFERENCES}

Adamaszek, M., D’Agata, F., Ferrucci, R., Habas, C., Keulen, S., Kirkby, K. C., et al. (2017). Consensus paper: cerebellum and emotion. Cerebellum 16, 552-576. doi: 10.1007/s12311-0160815-8

Amanzio, M., and Benedetti, F. (1999). Neuropharmacological dissection of placebo analgesia: expectation-activated opioid systems versus conditioning-activated specific subsystems. J. Neurosci. 19, 484-494. doi: 10.1523/JNEUROSCI.19-01-00484.1999

Amanzio, M., Benedetti, F., Porro, C. A., Palermo, S., and Cauda, F. (2011). Activation likelihood estimation meta-analysis of brain correlates of placebo
(Varanini et al., 2018). In addition, preliminary findings indicate higher interoceptive awareness in highs than in mediums and lows (Sebastiani et al., 2018).

Morfo-functional differences between highs and lows have been observed in the insula and other limbic structures (Landry et al., 2017) and in the cerebellar cortex (Picerni et al., 2018). They consist of reduced gray matter volume (Landry et al., 2017; Picerni et al., 2018) and in a paradoxical increase in pain perception and amplitude of the cortically evoked observed after transcranial anodal stimulation of the cerebellum (Bocci et al., 2017). These morphofunctional differences could sustain the observed hypnotizability-related difference in the role of interoception and of the Behavioral Inhibition/Activation System in pain experience. In fact, interoception contributes to emotion (Critchley and Garfinkel, 2017), the insula and the cerebellum are involved in interoception /interpretation of bodily signals and autonomic monitoring and control, respectively (Di Lernia et al., 2016; Kuehn et al., 2016; Lu et al., 2016; Schulz, 2016; Adamaszek et al., 2017).

\section{CONCLUSION}

As summarized in Figure 1, (a) hypnotizability is just one of the individual traits involved in the ability to control pain through suggestions of analgesia; (b) in highs any method of cognitive control could be poorly sustained by opioid mechnisms; (c) hypnotizability-related morfo-functional characteristics of limbic circuits and of the cerebellum may sustain differences in cognitive-emotional traits contributing to peculiar pain processing; (d) the efficacy of the suggestions of analgesia in patients with low hypnotizability can be due to placebo responses elicited by suggestions.

The socio-cognitive views of hypnotizability and hypnosis (Lynn and Green, 2011) are the best reference frame to interpret the relation among hypnotizability and pain control. In fact, they allow to consider the joined role of a number of individual traits and of situational variables in pain perception and cognitive control.

\section{AUTHOR CONTRIBUTIONS}

All authors listed have made a substantial, direct and intellectual contribution to the work, and approved it for publication. analgesia in human experimental pain. Hum. Brain Mapp. 34, 738-752. doi: $10.1002 / \mathrm{hbm} .21471$

Angelides, N. H., Gupta, J., and Vickery, T. J. (2017). Associating resting-state connectivity withrait impulsivity. Soc. Cogn. Affect. Neurosci. 12, 1001-1008. doi: 10.1093/scan/nsx031

Babel, P., Bajcar, E. A., Adamczyk, W., Kicman, P., Lisinska, N., Swider, K., et al. (2017). Classical conditioning without verbal suggestions elicits placebo analgesia and nocebo hyperalgesia. PLoS ONE 12:e0181856. doi: 10.1371/journal.pone.0181856

Bartošová, O., Polanecky, O., Perlik, F., Adamek, S., and Slanar, O. (2015). OPRM1 and $A B C B 1$ polymorphisms and their effect on postoperative pain relief with piritramide. Physiol. Res. 64(Suppl. 4), S521-S527. 
Benedetti, F. (2013). Placebo and the new physiology of the doctor-patient relationship. Physiol. Rev. 93, 1207-1246. doi: 10.1152/physrev.00043.2012

Benedetti, F., and Amanzio, M. (2013). Mechanisms of the placebo response. Pulm. Pharmacol. Ther. 26, 520-523. doi: 10.1016/j.pupt.2013.01.006

Benedetti, F., Arduino, C., and Amanzio, M. (1999). Somatotopic activation of opioid systems by target-directed expectations of analgesia. J. Neurosci. 19, 3639-3648. doi: 10.1523/JNEUROSCI.19-09-03639.1999

Berna, C., Tracey, I., and Holmes, E. A. (2012). How a better understanding of spontaneous mental imagery linked to pain could enhance imagerybased therapy in chronic pain. J. Exp. Psychopathol. 3, 258-273. doi: $10.5127 /$ jep.017911

Bocci, T., Barloscio, D., Parenti, L., Sartucci, F., Carli, G., and Santarcangelo, E. L. (2017). High hypnotizability impairs the cerebellar control of pain. Cerebellum 16, 55-61. doi: 10.1007/s12311-016-0764-2

Boswell, M. V., Stauble, M. E., Loyd, G. E., Langman, L., Ramey-Hartung, B., Baumgartner, R. N., et al. (2013). The role of hydromorphone and OPRM1 in postoperative pain relief with hydrocodone. Pain Physic. 16, e227-e235.

Braffman, W., and Kirsch, I. (1999). Imaginative suggestibility and hypnotizability: an empirical analysis. J. Pers. Soc. Psychol. 77, 578-587. doi: 10.1037/0022-3514.77.3.578

Carli, G., Suman, A. L., Biasi, G., Marcolongo, R., and Santarcangelo, E. L. (2008). Paradoxical experience of hypnotic analgesia in low hypnotizable fibromyalgic patients. Arch. ItalBiol. 146, 75-82.

Carlino, E., Frisaldi, E., and Benedetti, F. (2014). Pain and the context. Nat. Rev. Rheumatol. 10, 348-355. doi: 10.1038/nrrheum.2014.17

Carlson, L. E., Zelinski, E., Toivonen, K., Flynn, M., Qureshi, M., Piedalue, K. A., et al. (2017). Mind-body therapies in cancer: what is the latest evidence? Curr. Oncol. Rep. 19:67. doi: 10.1007/s11912-017-0626-1

Carver, C. S. (2004). Negative affects deriving from the behavioral approach system. Emotion 4, 3-22. doi: 10.1037/1528-3542.4.1.3

Critchley, H. D., and Garfinkel, S. N. (2017). Interoception and emotion. Curr. Opin. Psychol. 17, 7-14. doi: 10.1016/j.copsyc.2017.04.020

Critchley, H. D., and Harrison, N. A. (2013).Visceral influences on brain and behavior. Neuron 77, 624-638. doi: 10.1016/j.neuron.2013.02.008

Danziger, N., Fournier, E., Bouhassira, D., Michaud, D., De Broucker, T., Santarcangelo, E., et al. (1998). Different strategies of modulation can be operative during hypnotic analgesia: a neurophysiological study. Pain 75 , 85-92. doi: 10.1016/S0304-3959(97)00208-X

Dasse, M. N., Elkins, G. R., and Weaver, C. A. III. (2015). Correlates of the multidimensional construct of hypnotizability: paranormal belief, fantasy proneness, magical ideation, and dissociation. Int. J. Clin. Exp. Hypn. 63, 274-283. doi: 10.1080/00207144.2015.1031051

De Pascalis, V., Bellusci, A., and Russo, P. M. (2000). Italian norms for the stanford hypnotic susceptibility scale, Form C1. Int. J. Clin. Exp. Hypn. 48, 315-323. doi: $10.1080 / 00207140008415249$

De Pascalis, V., Magurano, M. R., and Bellusci, A. (1999). Pain perception, somatosensory event-related potentials and skin conductance responses to painful stimuli in high, mid, and low hypnotizable subjects: effects of differential pain reduction strategies. Pain 83, 499-508. doi: 10.1016/S0304-3959(99)00157-8

De Pascalis, V., and Scacchia, P. (2016). Hypnotizability 183 and placebo analgesia in waking and hypnosis as modulators of auditory startle responses in healthy women: an ERP study. PLOS ONE 11:e0159135. doi: 10.1371/journal.pone.0159135

De Pascalis, V., Varriale, V., and Cacace, I. (2015). Pain modulation in waking and hypnosis in women: event-related potentials and sources of cortical activity. PLoS ONE 10:e0128474. doi: 10.1371/journal.pone.0128474

De Pascalis, V., Varriale, V., and D'Antuono, L. (2010). Event-related components of the punishment and reward sensitivity. Clin. Neurophysiol. 121, 60-76. doi: 10.1016/j.clinph.2009.10.004

Del Casale, A., Ferracuti, S., Rapinesi, C., Serata, D., Caltagirone, S. S., Savoja, V., et al. (2015). Pain perception and hypnosis: findings from recent functional neuroimaging studies. Int. J. Clin. Exp. Hypn. 63, 144-170. doi: $10.1080 / 00207144.2015 .1002371$

Derbyshire, S. W., Whalley, M. G., and Oakley, D. A. (2009). Fibromyalgia pain and its modulation by hypnotic and non-hypnotic suggestion: an fMRI analysis. Eur. J. Pain 13, 542-550. doi: 10.1016/j.ejpain.2008. 06.010
Di Lernia, D., Serino, S., and Riva, G. (2016). Pain in the body. Altered interoception in chronic pain conditions: a systematic review. Neurosci. Biobehav. Rev. 71, 328-341. doi: 10.1016/j.neubiorev.2016.09.015

Didier, H., Marchetti, C., Borromeo, G., Tullo,V., D’Amico, D., Bussone, G., et al. (2011). Chronic daily headache: suggestion for the neuromuscular oral therapy. Neurol. Sci. 32 (Suppl. 1), S161-S164. doi: 10.1007/s10072-011-0515-6

Dillworth, T., Mendoza, M. E., and Jensen, M. P. (2012). Neurophysiology of pain and hypnosis for chronic pain. Transl. Behav. Med. 2, 65-72. doi: 10.1007/s13142-011-0084-5

Elkins, G., Jensen, M. P., and Patterson, D. R. (2007). Hypnotherapy for the management of chronic pain. Int. J. Clin. Exp. Hypn. 55, 275-287. doi: 10.1080/00207140701338621

Elkins, G. R., Barabasz, A. F., Council, J. R., and Spiegel, D. (2015). Advancing research and practice: the revised APA Division 30 definition of hypnosis. Int. J. Clin. Exp. Hypn. 63, 1-9. doi: 10.1080/00207144.2014.961870

Enea, V., Dafinoiu, I., Opris, D., and David, D. (2014). Effects of hypnotic analgesia and virtual reality on the reduction of experimental pain among high and low hypnotizables. Int. J. Clin. Exp. Hypn. 62, 360-377. doi: 10.1080/00207144.2014.901087

Faymonville, M. E., Roediger, L., Del Fiore, G., Delgueldre, C., Phillips, C., Lamy, M., et al. (2003). Increased cerebral functional connectivity underlying the antinociceptive effects of hypnosis. Brain Res. Cogn. Brain Res. 17, 255-262. doi: 10.1016/S0926-6410(03)00113-7

Feldman, J. B. (2009). Expanding hypnotic pain management to the a ffective dimension of pain. Am. J. Clin. Hypn. 51, 235-254. doi: 10.1080/00029157.2009.10401674

Fidanza, F., Varanini, M., Ciaramella, A., Carli, G., and Santarcangelo, E. L. (2017). Pain modulation as a function of hypnotizability: diffuse noxious inhibitory control induced by cold pressor test vs explicit suggestions of analgesia. Physiol. Behav. 171, 135-141. doi: 10.1016/j.physbeh.2017.01.013

Gearan, P., and Kirsch, I. (1993). Response expectancy as a mediator of hypnotizability modification: a brief communication. Int. J. Clin. Exp. Hypn. 41, 84-91. doi: 10.1080/002071493084 14539

Gong, X. D., Wang, J. Y., Liu, F., Yuan, H. H., Zhang, W. Y., Guo, Y. H., et al. (2013). Gene polymorphisms of OPRM1 A118G and ABCB1 C3435T may influence opioid requirements in Chinese patients with cancer pain. Asian Pac. J. Cancer Prev. 14, 2937-2943. doi: 10.7314/APJCP.2013.14.5.2937

Granot, M., Weissman-Fogel, I., Crispel, Y., Pud, D., Granovsky, Y., Sprecher, E., et al. (2008). Determinants of endogenous analgesia magnitude in a diffuse noxious inhibitory control (DNIC) paradigm: do conditioning stimulus painfulness, gender and personality variables matter? Pain 136, 142-149. doi: 10.1016/j.pain.2007.06.029

Gray, J. A. (1990). Brain systems that mediate both emotion and cognition. Cogn. Emot. 4, 269-288. doi: 10.1080/02699939008410799

Green, J. P., Barabasz, A. F., Barrett, D., and Montgomery, G. H. (2005). Forging ahead: the 2003 APA Division 30 definition of hypnosis. Int. J. Clin. Exp. Hypn. 53, 259-264. doi: 10.1080/00207140590961321

Green, J. P., and Lynn, S. J. (2011). Hypnotic responsiveness: expectancy, attitudes, fantasy proneness, absorption, and gender. Int. J. Clin. Exp. Hypn. 59, 103-121. doi: 10.1080/00207144.2011.522914

Hamlin, A. S., and Robertson, T. M. (2017). Pain and complementary therapies. Crit Care Nurs. ClinNorth Am. 229, 449-460. doi: 10.1016/j.cnc.2017.08.005

Hofbauer, R. K., Rainville, P., Duncan, G. H., and Bushnell, M. C. (2001). Cortical representation of the sensory dimension of pain. J. Neurophysiol. 86, 402-411. doi: $10.1152 /$ jn.2001.86.1.402

Huber, A., Lui, F., and Porro, C. A. (2013). Hypnotic susceptibility modulates brain activity related to experimental placebo analgesia. Pain 154, 1509-1518. doi: 10.1016/j.pain.2013.03.031

Hyland, M. E. (2011). Motivation and placebos: do different mechanisms occur in different contexts? Philos. Trans. R. Soc. Lond. B. Biol. Sci. 366, 1828-1837. doi: 10.1098/rstb.2010.0391

Iannetti, G. D., and Mouraux, A. (2010). From the neuromatrix to the pain matrix (and back). Exp Brain Res. 205,1-12. doi: 10.1007/s00221-010-2340-1

Ibanez-Marcelo, E.,Campioni, L., Phinyomark, A., Petri, G., and Santarcangelo, E. L. (2018). Topology highlights mesoscopic functional equivalence between imagery and perception. bioRxiv [Preprint]. Available online at: https://www. biorxiv.org/content/early/2018/02/20/268383 
Jensen, M. P., Barber, J., Romano, J. M., Hanley, M. A., Raichle, K. A., Molton, I. R., et al. (2009). Effects of self-hypnosis training and EMG biofeedback relaxation training on chronic pain in persons with spinal-cord injury. Int. J. Clin. Exp. Hypn. 57, 239-268. doi: 10.1080/00207140902881007

Jensen, M. P., Ehde, D., and Day, M. A. (2016). The behavioral activation and inhibition systems: implications for understanding and treating chronic pain. J. Pain 17, 529.e1-18. doi: 10.1016/j.jpain.2016.02.001

Jensen, M. P., and Patterson, D. R. (2014). Hypnotic approaches for chronic pain management: clinical implications of recent research findings. Am. Psychol. 9, 167-177. doi: 10.1037/a0035644

Jensen, M. P., Tan, G., and Chua, S. M. (2015). Pain intensity, headache frequency, and the behavioral activation and inhibition systems. Clin. J. Pain. 31, 1068-1074. doi: 10.1097/AJP.0000000000000215

Kasos, E., Kasos, K., Pusztai, F., Polyák, Á., Kovács, K. J., and Varga, K., (2018). Changes in oxytocin and cortisol in active-alert hypnosis: hormonal changes benefiting low hypnotizable participants. Int. J. Clin. Exp. Hypn. 66, 404-427. doi: 10.1080/00207144.2018.1495009

Khalsa, S. S., Adolphs, R., Cameron, O. G., Critchley, H. D., Davenport, P. W., Feinstein, J. et al. (2018). Interoception and mental health: a roadmap. Biol. Psychiatry Cogn. Neurosci. Neuroimag. 3, 501-513. doi: 10.1016/j.bpsc.2017.12.004

Kiernan, B. D., Dane, J. R., Phillips, L. H., and Price, D. D. (1995). Hypnotic analgesia reduces R-III nociceptive reflex: further evidence concerning the multifactorial nature of hypnotic analgesia. Pain 60, 39-47. doi: 10.1016/0304-3959(94)00134-Z

Kirsch, I. (2018). Response expectancy and the placebo effect. Int. Rev. Neurobiol. 138, 81-93. doi: 10.1016/bs.irn.2018.01.003

Koban, L., Jepma, M., Geuter, S., and Wager, T. D. (2017). What's in a word? How instructions, suggestions, and social information change pain and emotion. Neurosci. Biobehav. Rev. 81, 29-42. doi: 10.1016/j.neubiorev.2017.02.014

Kuehn, E., Mueller, K., Lohmann, G., and Schuetz-Bosbach, S. (2016). Interoceptive awareness changes the posterior insula functional connectivity profile. Brain Struct. Funct. 221, 1555-1571. doi: 10.1007/s00429-015-0989-8

Landry, M., Lifshitz, M., and Raz, A. (2017). Brain correlates of hypnosis: a systematic review and meta-analytic exploration. Neurosci. Biobehav. Rev. 81(Pt A), 75-98. doi: 10.1016/j.neubiorev.2017.02.020

Legrain, ,V., Iannetti, G. D., Plaghki, L., and Mouraux, A. (2011). The pain matrix reloaded: a salience detection system for the body. Prog. Neurobiol. 93, 111-124. doi: 10.1016/j.pneurobio.2010.10.005

Lu, C., Yang, T., Zhao, H., Zhang, M., Meng, F., Fu, H., et al. (2016). Insular cortex is critical for the perception, modulation, and chronification of pain. Neurosci Bull. 32, 191-201. doi: 10.1007/s12264-016-0016-y

Lynn, S. J., and Green, J. P. (2011).The sociocognitive and dissociation theories of hypnosis: toward a rapprochement. Int. J. Clin. Exp. Hypn. 59, 277-293. doi: 10.1080/00207144.2011.570652

Madeo, D., Castellani, E., Mocenni, C., and Santarcangelo, E. L. (2015). Pain perception and EEG dynamics: does hypnotizability account for the efficacy of the suggestions of analgesia? Physiol. Behav. 145, 57-63. doi: 10.1016/j.physbeh.2015.03.040

Mendoza, M. E., Capafons, A., Gralow, J. R., Syrjala, K. L., Suarez-Rodriguez, J. M., Fann, J. R., et al. (2017a). Randomized controlled trial of the Valencia model of waking hypnosis plus CBT for pain, fatigue, and sleep management in patients with cancer and cancer survivors. Psychooncology 26, 1832-1838. doi: $10.1002 /$ pon. 4232

Mendoza, M. E., Capafons, A., and Jensen, M. P. (2017b). Hypnosis attitudes: treatment effects and associations with symptoms in individuals with cancer. Am. J. Clin. Hypn. 60, 50-67. doi: 10.1080/00029157.2017.1300570

Meyer, E. C., and Lynn, S. J. (2011). Responding to hypnotic and nonhypnotic suggestions: performance standards, imaginative suggestibility, and response expectancies. Int. J. Clin. Exp. Hypn. 59, 327-349. doi: 10.1080/00207144.2011.570660

Milling, L. S., Kirsch, I., Allen, G. J., and Reutenauer, E. L. (2005). The effects of hypnotic and nonhypnotic imaginative suggestion on pain. Ann. Behav. Med. 29, 116-127. doi: 10.1207/s15324796abm2902_6

Milling, L. S., Reardon, J. M., and Carosella, G. M. (2006). Mediation and moderation of psychological pain treatments: response expectancies and hypnotic suggestibility. J. Consult. Clin. Psychol. 74, 253-262. doi: 10.1037/0022-006X.74.2.253
Milling, L. S., Shores, J. S., Coursen, E. L., Menario, D. J., and Farris, C. D. (2007) Response expectancies, treatment credibility, and hypnotic suggestibility: mediator and moderator effects in hypnotic and cognitive-behavioral pain interventions. Ann. Behav. Med. 33, 167-178. doi: 10.1007/BF02879898

Montgomery, G. H., David, D., Winkel, G., Silverstein, J. H., and Bovbjerg, D. H. (2002a). The effectiveness of adjunctive hypnosis with surgical patients: a meta-analysis. Anesth Analg. 94, 1639-1645.

Montgomery, G. H., Weltz, C. R., Seltz, M., and Bovbjerg, D. H. (2002b). Brief presurgery hypnosis reduces distress and pain in excisional breast biopsy patients. Int. J. Clin. Exp. Hypn. 50, 17-32. doi: 10.1080/00207140208410088

Moret, V., Forster, A., Laverriere, M. C., Lambert, H., Gaillard, R. C., Bourgeois, P., et al. (1991). Mechanism of analgesia induced by hypnosis and acupuncture: is there a difference? Pain 45, 135-140. doi: 10.1016/0304-3959(91)90178-Z

Murphy, J., Brewer, R., Catmur, C., and Bird, G. (2017). Interoception and psychopathology: a developmental neuroscience perspective. Dev. Cogn. Neurosci. 23, 45-56. doi: 10.1016/j.dcn.2016.12.006

Papalia, E., Manzoni, D., and Santarcangelo, E. L. (2014).Stabilizing posture through imagery. Int. J. Lin. Exp. Hypn. 62, 292-309. doi: 10.1080/00207144.2014.901080

Peciña, M., and Zubieta, J. K. (2015). Molecular mechanisms of placebo responses in humans. Mol. Psychiatry 20, 416-423. doi: 10.1038/mp.2014.164

Petrovic, P., Kalso, E., Petersson, K. M., and Ingvar, M. (2002). Placebo and opioid analgesia: imaging a shared neuronal network. Science 295, 1737-1740. doi: $10.1126 /$ science.1067176

Picerni, E., Santarcangelo, E. L., Laricchiuta, D., Cutuli, D., Petrosini, L., Spalletta, G., et al. (2018). Cerebellar structural variations in subjects with different hypnotizability. Cerebellum. doi: 10.1007/s12311-018-0965-y. [Epub ahead of print].

Presciuttini, S., Sciarrino, R., Curcio, M., Scatena, F., Jensen, M. P., and Santarcangelo, E. (2018). Polymorphism of opioids receptors $\mu 1$ in highly hypnotizable subjects. Int. J. Clin. Exp. Hypn. 66, 106-118. doi: 10.1080/00207144.2018.1396128

Rainville, P., Duncan, G. H., Price, D. D., Carrier, B., and Bushnell, M. C. (1997). Pain affect encoded in human anterior cingulate but not somatosensory cortex. Science 277, 968-971.

Raz, A. (2007). Suggestibility and hypnotizability: mind the gap. Am. J. Clin. Hypn. 49, 205-210. doi: 10.1080/00029157.2007.10401582

Ren, Z. Y., Xu, X. Q., Bao, Y. P., He, J., Shi, L., Deng, J. H., et al. (2015). The impact of genetic variation on sensitivity to opioid analgesics in patients with postoperative pain: a systematic review and meta-analysis. Pain Physician 18, 131-152.

Sandrini, G., Milanov, I., Malaguti, S., Nigrelli, M. P., Moglia, A., and Nappi, G. (2000). Effects of hypnosis on diffuse noxious inhibitory controls. Physiol. Behav. 69, 295-300. doi: 10.1016/S0031-9384(00)00210-9

Santarcangelo, E. L. (2014). New views of hypnotizability. Front. Behav. Neurosci. 8:224. doi: 10.3389/fnbeh.2014.00224

Santarcangelo, E. L., and Scattina, E. (2016). Complementing the latest APA definition of hypnosis: sensory-motor and vascular peculiarities involved in hypnotizability. Int. J. Clin. Exp. Hypn. 64, 318-330. doi: 10.1080/00207144.2016.1171093

Santarcangelo, E. L., Varanini, M., Paoletti, G., Castellani, E., Palombo, C., and Carli, G. (2013). Pain-inducing imagery as a function of hypnotisability and of the activity of Gray's Behavioral Inhibition/Activation Systems. Neurosci. Lett. 557 Pt B, 184-187. doi: 10.1016/j.neulet.2013.06.049

Schulz, S. M. (2016). Neural correlates of heart-focused interoception: a functional magnetic resonance imaging meta-analysis. Phil. Trans. R. Soc. Lond. B 371:20160018. doi: 10.1098/rstb.2016.0018

Scott, D. J., Stohler, C. S., Egnatuk, C. M., Wang, H., Koeppe, R. A., and Zubieta, J. K. (2008). Placebo and nocebo effects are defined by opposite opioid and dopaminergic responses. Arch. Gen. Psychiatry 65, 220-231. doi: 10.1001/archgenpsychiatry.2007.34

Sebastiani, L., Diolaiuti, F., Huber, A., Ciaramella, A., and Santarcangelo, E. L. (2018). Interoceptive aewareness, conditioned emotion and hypnotisability. Int. J. Psychophysiol. 131S:S147.

Serrano-Ibáñez, E. R., Ramírez-Maestre, C., López-Martínez, A. E., Esteve, R. Ruiz-Párraga, G. T., and Jensen, M. P. (2018). Behavioral inhibition and activation systems, and emotional regulation in individuals with chronic musculoskeletal pain. Front. Psychiatry. 9:394. doi: 10.3389/fpsyt.2018.00394 
Sia, A. T., Lim, Y., Lim, E. C., Ocampo, C. E., Lim, W. Y., Cheong, P., et al. (2013). Influence of mu-opioid receptor variant on morphine use and self-rated pain following abdominal hysterectomy. J. Pain 14, 1045-1052. doi: 10.1016/j.jpain.2013.03.008

Stoelb, B. L., Molton, I. R., Jensen, M. P., and Patterson, D. R. (2009). The efficacy of hypnotic analgesia in adults: a review of the literature. Contemp. Hypn. 26, 24-39. doi: 10.1002/ch.370

Trescot, A. M., and Faynboym, S. (2014). A review of the role of genetic testing in pain medicine. Pain Physician 17, 425-445.

Valentini, E., Betti, V., Hu, L., and Aglioti, S. M. (2013). Hypnotic modulation of pain perception and of brain activity triggered by nociceptive laser stimuli. Cortex 49, 446-462. doi: 10.1016/j.cortex.2012.02.005

Varanini, M., Balocchi, R., Carli, G., Paoletti, G., and Santarcangelo, E. L. (2018). Hypnotizability and pain modulation: a body-mind perspective. Int J. Clin. Exp. Hypn. 66, 265-281. doi: 10.1080/00207144.2018.1460561

Waisblat, V., Langholz, B., Bernard, F. J., Arnould, M., Benassi, A., Ginsbourger, F., et al. (2017). Impact of a hypnotically-based intervention on pain and fear in women undergoing labor. Int. J. Clin. Exp. Hypn. 65, 64-85. doi: 10.1080/00207144.2017.1246876

Wan, X. S., Song, H. B., Chen, S., Zhang, W., Liu, J. Q., Huang, C., et al. (2015). Association of single nucleotide polymorphisms of ABCB1, OPRM1 and COMT with pain perception in cancer patients. J. Huazhong Univ. Sci. Technol. 35, 752-758. doi: 10.1007/s11596-015-1502-6

Yao, P., Ding, Y. Y., Wang, Z. B., Ma, J. M., Hong, T., and Pan, S. N. (2015). Effect of gene polymorphism of COMT and OPRM1 on the preoperative pain sensitivity in patients with c cancer. Int. J. Clin. Exp. Med. 8, 10036-10039.

Zachariae, R., and Bjerring, P. (1994). Laser-induced pain-related brain potentials and sensory pain ratings in high and low hypnotizable subjects during hypnotic suggestions of relaxation, dissociated imagery, focused analgesia, and placebo. Int. J. Clin. Exp. Hypn. 42, 56-80. doi: 10.1080/00207149408409341

Zeev-Wolf, M., Goldstein, A., Bonne, O., and Abramowitz, E. G. (2016). Hypnotically induced somatosensory alterations: toward a neurophysiological understanding of hypnotic anaesthesia. Neuropsychologia 87, 182-191. doi: 10.1016/j.neuropsychologia.2016.05.020

Zhang, Y., Wang, D., Johnson, A. D., Papp, A. C., and Sadee, W. (2005). Allelic expression imbalance of human mu opioid receptor (OPRM1) caused by variant A118G. J. Biol. Chem. 280, 32618-32624. doi: 10.1074/jbc.M504942200

Zubieta, J. K., Bueller, J. A., Jackson, L. R., Scott, D. J., Xu, Y., Koeppe, R. A., et al. (2005). Placebo effects mediated by endogenous opioid activity on mu-opioid receptors. J. Neurosci. 25, 7754-7762. doi: 10.1523/JNEUROSCI.0439-05.2005

Zunhammer, M., Bingel, U., Wager, T. D., and Placebo Imaging Consortium (2018). Placebo effects on the neurologic pain signature: a meta-analysis of individual participant functional magnetic resonance imaging data. JAMA Neurol. 75, 1321-1330. doi: 10.1001/jamaneurol.2018.2017

Conflict of Interest Statement: The authors declare that the research was conducted in the absence of any commercial or financial relationships that could be construed as a potential conflict of interest.

Copyright (c) 2018 Santarcangelo and Consoli. This is an open-access article distributed under the terms of the Creative Commons Attribution License (CC BY). The use, distribution or reproduction in other forums is permitted, provided the original author(s) and the copyright owner(s) are credited and that the original publication in this journal is cited, in accordance with accepted academic practice. No use, distribution or reproduction is permitted which does not comply with these terms. 